Supporting Information

\title{
Understanding the specific heat enhancement in metal-containing nanofluids for thermal energy storage: experimental and ab-initio evidence for a strong interfacial layering effect
}

Iván Carrillo-Berdugo ${ }^{\dagger}$ Scott D. Midgley,${ }^{\ddagger}$ Ricardo Grau-Crespo,${ }^{\ddagger}$ David Zorrilla,${ }^{\dagger}$ Javier Navas $^{\dagger, *}$

${ }^{\dagger}$ Departamento de Química Física, Facultad de Ciencias, Universidad de Cádiz, E-11510 Puerto Real (Cádiz), Spain.

¥Department of Chemistry, School of Chemistry, Food and Pharmacy, University of Reading, United Kingdom, RG6 6AD

${ }^{*}$ Corresponding author: javier.navas@uca.es (J. Navas) 


\section{Supplementary Information for section 3.1. Characterization of Pd nanoplates}

Figure S1 shows the XPS general survey spectrum for the as-synthesized sample containing Pd nanoplates. Cl 2p and N 1s transitions in the 211-192 eV and 410-392 eV spectral regions, respectively, are likely to appear due to the presence of residual traces of $\mathrm{Cl}^{-}$(from the metal precursor) or PVP (the reductant and stabilizer) adsorbed on Pd nanoplates. Pd $3 \mathrm{~d}$ transitions in the 350-328 eV region were chosen for determination of Pd metal, as discussed in the main document. The $\mathrm{Pd} 3 \mathrm{p}$ transition in the $572-522 \mathrm{eV}$ region would be ideally better (in terms of intensity and resolution) for such purpose but, as shown in Figure $\mathrm{S} 2$, the $\mathrm{Pd} 3 \mathrm{p}_{3 / 2}$ spinorbit component overlaps with the peak from $\mathrm{O} 1 \mathrm{~s}$ transition. It is noteworthy that the $\mathrm{O} 1 \mathrm{~s}$ transition does not appear below $530 \mathrm{eV}$, which is indicative of the oxygen not being part of a metal oxide structure but of any organic $\mathrm{C}=\mathrm{O}$ or $\mathrm{C}-\mathrm{O}$ from a molecule adsorbed during sample manipulation (namely $\mathrm{CO}_{2}$, ethanol or acetone). $\mathrm{Pd} \mathrm{MNN}$ and $\mathrm{Pd} \mathrm{MNV}$ Auger emissions were also assigned for reinforcement of the Pd metal determination.

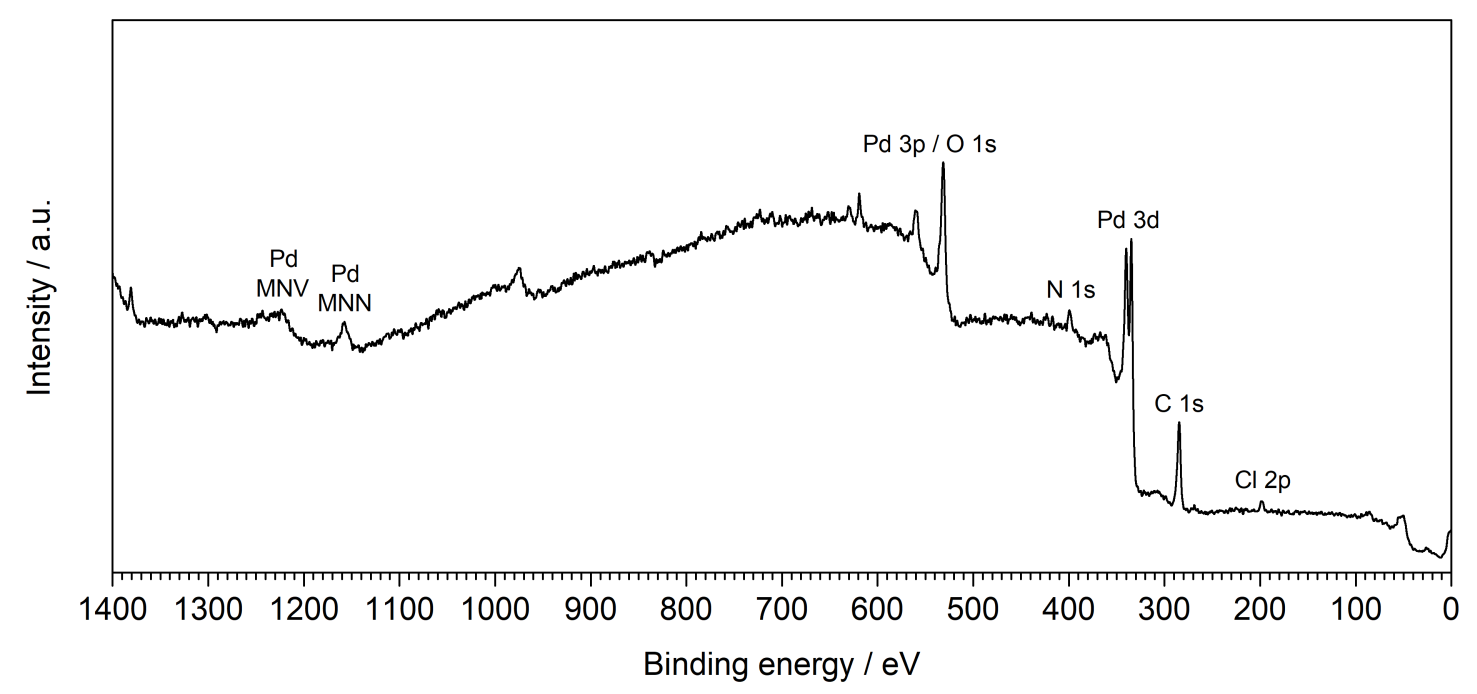

Figure S1. X-ray photoelectron general survey spectrum for Pd nanoplates. 


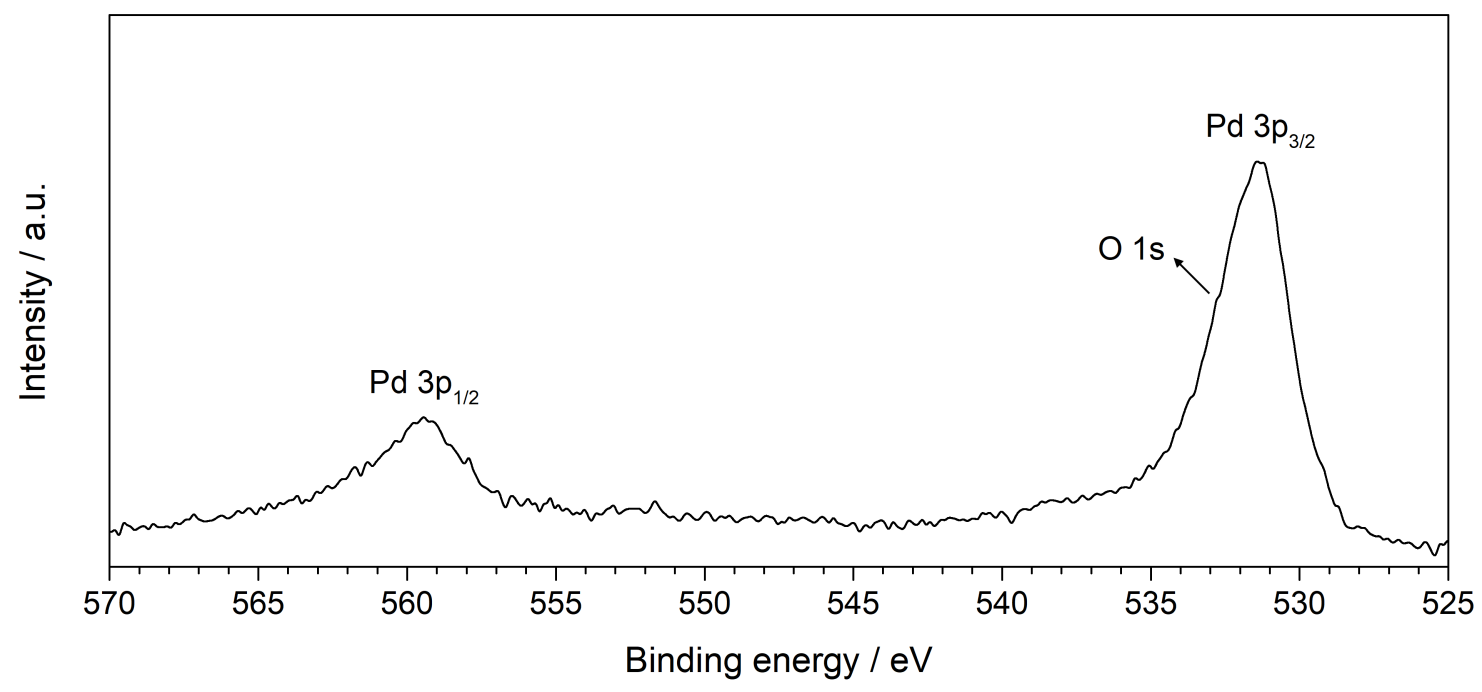

Figure S2. X-ray photoelectron spectrum ( $\mathrm{Pd} 3 \mathrm{p}$ region) for Pd nanoplates. 